\title{
Severe pulmonary dysfunction following acute respiratory distress syndrome
}

\author{
HR Smith, DG Sinclair
}

\begin{abstract}
Summary
Recovery of lung function following the acute respiratory distress syndrome (ARDS) is thought to be related to the severity of the initial insult. We report a case demonstrating virtually complete functional recovery following severe ARDS. The significance of this and the need for comprehensive follow-up of such patients is discussed.
\end{abstract}

Keywords: acute respiratory distress syndrome

A 25-year-old man fell from a fourth floor balcony sustaining pelvic and right femoral fractures with right-sided pulmonary contusions. Initial resuscitation included transfusion of 10 units of blood. Thirty six hours after the initial insult he developed respiratory failure and volume cycled ventilation was initiated. All the necessary criteria for a diagnosis of acute respiratory distress syndrome (ARDS) were fulfilled. ${ }^{1} \mathrm{He}$ was subsequently transferred to a tertiary referral centre where pressure-controlled inverse ratio ventilation was instituted. The subsequent clinical course was dominated by profound respiratory failure (arterial oxygen tension/inspired oxygen fraction of $8.8 \mathrm{Kpa}$ ) complicated by the development of multiple, bilateral pneumothoraces necessitating the insertion of multiple intercostal drains. Mechanical ventilation was required for 55 days.

Four months after the initial injury his orthopaedic problems had resolved. However, rehabilitation was limited by severe exertional dyspnoea and he was referred to this unit for further assessment. Resting arterial saturation $\left(\mathrm{SaO}_{2}\right)$ breathing air was $92 \%$. On minimal effort such as moving from bed to chair $\mathrm{SaO}_{2}$ fell to $86 \%$. Lung function tests showed a restrictive defect with significant impairment of carbon monoxide transfer (table). A computed tomographic scan (CT) of the thorax at this time demonstrated multiple, bilateral loculated pneumothoraces with bullae and areas of atelectasis (figure 1). Operative intervention was considered, but delayed due to his poor physical and nutritional status. Over the following months his symptoms began to spontaneously resolve with improvements in his physical condition and CT appearance (figure 2).

Reassessment of lung function six and 12 months post injury demonstrated continuing improvement reflected in an increasing exercise tolerance. One year after injury he underwent a progressive work test, achieving a maximal oxygen uptake $\left(\mathrm{VO}_{2} \mathrm{max}\right)$ of $3.0 \mathrm{l}$ min, $\mathrm{SaO}_{2}$ remaining greater than $95 \%$ throughout.

\section{Discussion}

This case demonstrates a remarkable spontaneous recovery, following severe ARDS complicated by barotrauma, which would not be

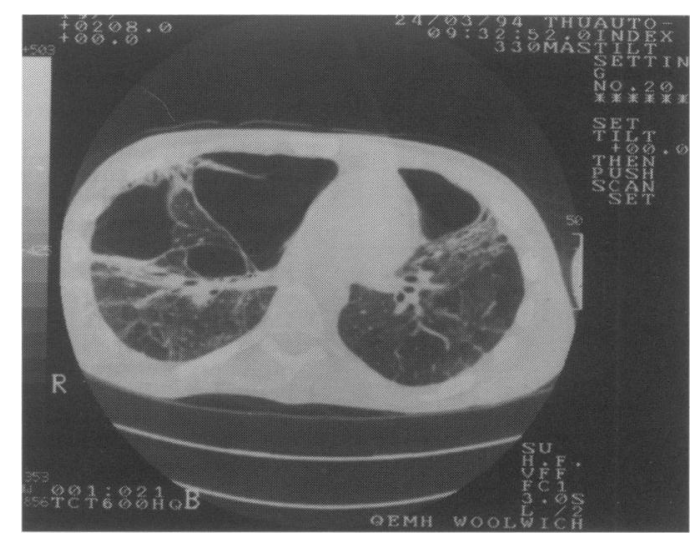

Figure 1 CT scan of thorax four months post-injury demonstrating bilateral pneumothoraces with bullae and areas of atelectasis. No evidence of inflammatory infiltrations
Army Chest Unit, Cambridge Military Hospital, Aldershot, Hants GU11 2AN, UK HR Smith DG Sinclair

Correspondence to Dr DG Sinclair,

Consultant Respiratory Physician, Torbay Hospital, Laws Bridge, Torquay TQ2 7AA, UK

Accepted 22 November 1995
Table Sequential measurements of spirometry (FEV1/FVC), available volume for gas transfer (VA), total carbon monoxide transfer capacity (TLCO) and carbon monoxide transfer coefficient (KCO)

\begin{tabular}{|c|c|c|c|c|}
\hline $\begin{array}{l}\text { Months } \\
\text { post injury }\end{array}$ & $\begin{array}{l}F E V 1 / F V C \\
\text { (predicted value } 5.1 / 6.2 l \text { ) }\end{array}$ & $\begin{array}{l}V A \\
\text { (\% predicted) }\end{array}$ & $\begin{array}{l}\text { TLCO } \\
\text { (\% predicted) }\end{array}$ & $\begin{array}{l}\text { KCO } \\
\text { (\% predicted) }\end{array}$ \\
\hline 4 & $1.47 / 1.77$ & 27 & 20 & 52 \\
\hline 6 & $2.1 / 3.08$ & 39 & 31 & 78 \\
\hline 12 & $2.8 / 4.1$ & 82 & 70 & 85 \\
\hline
\end{tabular}


Figure 2 CT scan of the thorax seven months postinjury demonstrating substantial resolution

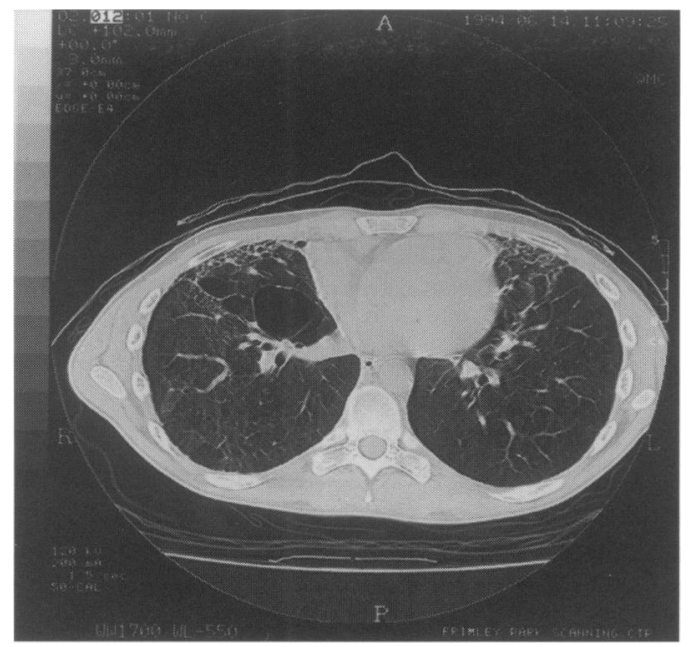

Possible predictors of respiratory dysfunction one year after ARDS

- severity of initial gas exchange abnormality

- initial required $\mathrm{FiO}_{2}$

- initial level of positive end expiratory pressure used

- ventilatory mode

Summary
- survival for ARDS remains unchanged in
20 years
- satisfactory predictors for long-term pulmonary
dysfunction in ARDS are lacking

predicted by the current literature. ${ }^{2}$ It was our expectation that operative intervention, possibly including lung transplantation, would be required.

Such studies as have been conducted on survivors of ARDS have generated conflicting opinion. Although many series report that the majority of survivors of ARDS are sympton free, ${ }^{3}$ more recent studies have suggested that in excess of $50 \%$ of survivors will experience respiratory symptoms. ${ }^{4,5}$ Abnormalities of gas transfer, lung volume and flow thought to be due to fibroproliferative changes in the lung can be demonstrated in some patients at one year. ${ }^{2}$ It remains uncertain as to which factors predict continuing respiratory disability or recovery following ARDS. It has been suggested that severe ARDS and the presence of

1 Gordon RB, Antonio A, Brigham KL, et al. The AmericanEuropean consensus conference on ARDS: definitions, mechanisms, relevant outcomes, and clinical trial coordination. Am $\mathcal{F}$ Respir Crit Care Med 1994; 149: 81824.

2 Hert R, Albert RK. Sequelae of the adult repiratory distress syndrome. Thorax 1994; 49: 8-13.

3 Douglas M, Downs J. Pulmonary function following severe acute respiratory failure and high levels of positive endexpiratory pressure. Chest 1977; 71: 18-23.

4 Peters J, Bell R, Prihoda T, Harris G, Andrews C, Johanson W. Clinical determinants of abnormalities in pulmonary functions in survivors of the adult respiratory distress fynctions in survivors of the adult respiratory barotrauma are associated with persistent abnormalities of carbon monoxide transfer. ${ }^{6}$ Alternatively, other studies have found no relationship between these variables and longterm recovery. ${ }^{7}$

Much effort has been directed, with little success, towards reducing the mortality of ARDS. Conversely, little attention has been paid to the morbidity of survivors, although it has been suggested that some supportive therapies may exacerbate the degree of pulmonary dysfunction in survivors. ${ }^{2}$

This case highlights the requirement for comprehensive follow-up of all survivors of ARDS in order that their management is directed not only towards initial survival but also to the reduction of long-term pulmonary dysfunction.

5 Halvey A, Sirik Z, Yehuda G, Lewinson G. Long-term evaluation of patients following the adult respiratory distres syndrome. Respir Care 1984; 29: 132-7.

6 Elliott G, Rasmusson B, Crapo R, Morris A, Jenson R. Prediction of pulmonary function abnormalities after adult respiratory distress syndrome (ARDS). Am Rev Respir Dis 1987; 135: 634-8. following the adult respiratory distress syndrome. Chest 1978; 74: $247-50$.
7 Yahav J, Lieberman P, Mollo M. Pulmonary function 